\title{
NURSES' ATTITUDES TOWARD INTERVENING WITH SMOKERS: THEIR KNOWLEDGE, OPINION AND E-LEARNING IMPACT
}

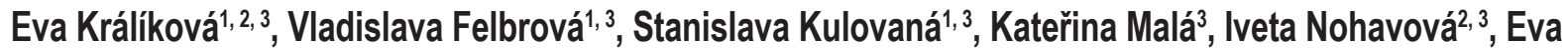

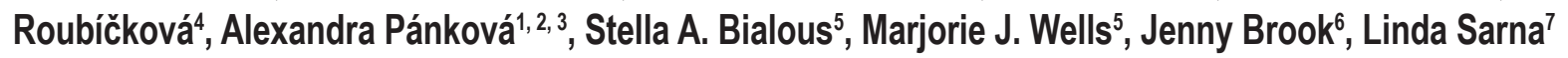 \\ ${ }^{1}$ Centre for Tobacco-Dependent, 3rd Department of Medicine, 1st Faculty of Medicine, Charles University and General University Hospital, \\ Prague, Czech Republic \\ ${ }^{2}$ Institute of Hygiene and Epidemiology, 1st Faculty of Medicine, Charles University and General University Hospital, Prague, Czech Republic \\ ${ }^{3}$ Society for Treatment of Tobacco Dependence, Prague, Czech Republic \\ ${ }^{4}$ Radiotherapy and Oncology Clinic, Faculty Hospital Královské Vinohrady, Prague, Czech Republic \\ ${ }^{5}$ School of Nursing, University of California, San Francisco, California, USA \\ ${ }^{6}$ David Geffen School of Medicine, University of California, Los Angeles, California, USA \\ ${ }^{7}$ School of Nursing, University of California, Los Angeles, California, USA
}

\section{SUMMARY}

Background: Numbering about 90,000, nurses represent the largest group of health care providers in the Czech Republic. Therefore, nurses can make a significant impact in the treatment of tobacco dependence, particularly in applying brief interventions to smokers.

Methods: During 2014, 279 nurses from the Czech Republic participated in an e-learning education programme consisting of two Webcasts with additional web-based resources about smoking cessation in relation to health and treatment options in daily clinical practice, particularly regarding brief intervention methods. Before viewing the e-learning programme, and three months after viewing it, the nurses completed a questionnaire documenting their interventions with smokers and their knowledge, attitudes and opinions regarding nurses' roles in smoking cessation.

Results: The responses in all of the following categories significantly improved: usually/always asking patients about smoking from $58 \%$ to $69 \%$ (OR 1.62, $\mathrm{Cl}=1.14-2.29, \mathrm{p}=0.007)$; recommendations to stop smoking from $56 \%$ to $66 \%(\mathrm{OR} 1.46, \mathrm{Cl}=1.03-2.06, \mathrm{p}=0.03)$; assessing willingness to quit from $49 \%$ to $63 \%$ (OR 1.72, $\mathrm{Cl}=1.23-2.42, \mathrm{p}=0.002)$; assisting with cessation from $21 \%$ to $33 \%(\mathrm{OR} 1.85, \mathrm{Cl}=1.26-2.71, \mathrm{p}=0.002)$; and recommending a smoke-free home from $39 \%$ to $58 \%(\mathrm{OR} 2.16, \mathrm{Cl}=1.54-3.04, \mathrm{p}<0.001)$. The increase in arranging follow-up from $7 \%$ to $10 \%$ did not constitute a statistically significant improvement, however, this finding is understandable in relation to the status of nurses in the Czech Republic. However, nurses' confidence in helping smokers to quit smoking, their senses of responsibility and determining the appropriateness of these interventions remains inadequate.

Conclusion: The nurses' brief intervention skills improved significantly after the completion of the e-learning programme, even though reservations remain among this group. The systematic education of nurses aimed at smoking cessation intervention and analyzing their motivation for treatment may contribute to improved nursing care, and thus lead to a reduction of smoking prevalence in the general population.

Key words: nurses, smoking cessation, education, e-learning, Czech Republic, attitude, opinion

Address for correspondence: E. Králiková, Institute for Hygiene and Epidemiology, Studničkova 7, 12800 Prague, Czech Republic. E-mail: eva.kralikova@lf1.cuni.cz

http://dx.doi.org/10.21101/cejph.a4652

\section{INTRODUCTION}

Active smoking (diagnosis F17.2 - mental disorders and behavioural changes caused by tobacco use, dependence syndrome) or passive exposure to tobacco smoke (diagnosis Z58.7) is responsible for one sixth of all deaths in the Czech Republic (1). Nearly $30 \%$ of the population over 15 years of age smoke, which is more than 2 million people (2). Tobacco dependence is the leading preventable risk factor for morbidity and mortality among non-communicable diseases (3).
Nurses are the largest group of health care professionals $(90,000)$ in the Czech Republic; they number almost three times as many as the country's physicians $(35,000)$. If every nurse would help just one patient to quit smoking per year, it would result in approximately 90,000 smokers quitting smoking each year. A significant barrier to making this a reality is the individual smoking status of nurses. Unfortunately, around $40 \%$ of Czech nurses smoke (4), which is much higher rate than that of $7 \%$ reported in the USA (5). Furthermore, appropriate training of nurses in tobacco cessation interventions with smokers is lacking, 
including developing the requisite knowledge, motivation, and awareness to provide smoking cessation interventions with their patients who smoke in the clinical setting. This type of training includes asking about smoking, recommending stopping to those who smoke, assessing patients' readiness to quit, and advising patients about treatment options (at minimum, by a handout or a recommendation to visit a nearby specialty treatment centre) or arranging for a control visit (6). This protocol is also included in the standard Czech nursing guidelines (7). At a minimum, the brief intervention should be a standard component of quality nursing care, as it is widely practiced in developed countries (8).

Smoking contributes to one-third of all cancer cases, yet, despite this fact, little attention is paid to oncology care for smoking. Patients often state after a cancer diagnosis, "It doesn't make sense to stop now." But, in reality, the opposite is true and quitting remains critically important.

Information on smoking is often missing in medical and nursing documentation, and in oncology treatment evaluation, even though smoking significantly influences the treatment outcomes. When oncology patients stop smoking, survival and quality of life is significantly improved. Smoking also increases complications following surgery and slows down wound healing, decreases radiotherapy and chemotherapy effects, and increases the incidence of adverse effects (9). Thus, quitting smoking significantly enhances quality of life as well as saving money not only to patients but also to the whole healthcare system by decreasing smoking-related complications. Additionally, nurses should recommend smoke free home environments to their patients and families to facilitate health and well-being (passive smoking diagnosis Z58.7).

\section{Design}

A prospective single-group design was used, with pre- and 3-month follow-up after an educational programme.

\section{MATERIALS AND METHODS}

The e-learning educational programme for nurses was developed in collaboration with the International Society of Nurses in Cancer Care (ISNCC) and the nursing section of the Society for Treatment of Tobacco Dependence (STTD). The topic was not only morbidity and mortality related to tobacco, especially in relation to oncology, but very importantly, the treatment and intervention options, including the scheme and importance of the short intervention, which is possible in every day nursing practice.

The e-learning programme contained a total of 94 slides and scripts divided into two 30-minute webcasts, "The role of nurses in smoking cessation" and "Smoking cessation within oncology settings". The webcasts included general data on tobacco use and control in the Czech Republic, the health impact of tobacco use and benefits of cessation including how to help smokers quit smoking, the benefits of cessation in oncology patients and the role of the nurse in tobacco control. The webcasts could be accessed on the ISNCC website where additional resources including a list of cessation services could be found. The e-learning participation for Czech nurses was taking care of adult patients and was provided free of charge.
Before viewing the programme, the nurses were asked to complete a 32-item web-based questionnaire assessing changes in nurses' delivery of smoking cessation interventions.

The questionnaire asked their demographic (age, sex) and professional characteristics (clinical specialty, education, years in nursing), and smoking status. Additionally, questions regarding the frequency (always, usually, sometimes, rarely, never) of nurses' interventions with patients who smoke using the five A's (Ask, Advise, Assess, Assist and Arrange) as well as their knowledge, and opinions regarding tobacco control in general and intervening with smokers to help them quit. The questionnaire was anonymous but each nurse could choose to state either her/his nickname (or use a real name) and e-mail address, so that a 3-month survey request (in which most of the questions were repeated) could be mailed to them. Neither their name, nickname, nor their e-mail address were connected with the evaluation of the results. The project was approved both by the Institutional Review Board (IRB) at the University of California, Los Angeles, California, USA and by the Ethics Committee at the Faculty Hospital in Prague. If the nurse wished to state her/his name at the end of the second survey, she/he then received a continuing

\section{Table 1. Demographic data of respondents}

\begin{tabular}{|l|c|c|}
\hline & Mean & SD \\
\hline Age (years) & 42.83 & 9.37 \\
\hline Years of clinical practice & 20.84 & 10.67 \\
\hline & Number & $\%$ \\
\hline
\end{tabular}

Gender $(\mathrm{N}=275)^{*}$

\begin{tabular}{|l|c|c|}
\hline Female & 270 & 98.18 \\
\hline Male & 5 & 1.82 \\
\hline
\end{tabular}

Smoking $(\mathrm{N}=278)^{* *}$

\begin{tabular}{|l|c|c|}
\hline Never & 159 & 57.19 \\
\hline In the past (former smoker) & 72 & 25.90 \\
\hline Current (current smoker) & 47 & 16.91 \\
\hline
\end{tabular}

Education $(\mathrm{N}=275)^{\star}$

\begin{tabular}{|l|c|c|}
\hline Nursing assistant & 4 & 1.45 \\
\hline Registered nurse & 183 & 66.55 \\
\hline Qualified nurse & 33 & 12.00 \\
\hline Bachelor & 31 & 11.27 \\
\hline Masters & 24 & 8.73 \\
\hline
\end{tabular}

Place of work $(\mathrm{N}=279)$

\begin{tabular}{|l|c|c|}
\hline Medical & 60 & 21.51 \\
\hline Surgical & 50 & 17.92 \\
\hline Acute/Intensive care & 27 & 9.68 \\
\hline Oncology & 35 & 12.54 \\
\hline ICU/Trauma unit & 6 & 2.15 \\
\hline Labour and delivery & 5 & 1.79 \\
\hline Gynaecology & 4 & 1.43 \\
\hline Psychiatric/Neurology & 11 & 3.94 \\
\hline Long term care/Rehabilitation & 21 & 7.53 \\
\hline Ambulatory/Primary care/Emergency room & 60 & 21.51 \\
\hline
\end{tabular}

*4 participants did not respond, **1 participant did not answer 
education certificate from the Czech Nurses Association (CNA) comprising three credits. The project was advertised both on the STTD and CNA web sites, as well as during nursing conferences and seminars. Only nurses who completed both questionnaires (baseline and after 3 months) were included into the analysis.

\section{Statistical Methods}

All analyses were done using SAS 9.4. To describe sample demographics, means with standard deviations were calculated for all continuous variables, while frequency and percent were calculated for the categorical variables (Table 1). Change in attitudes from baseline to 3 months was analyzed using Friedman's chi-square test (Table 2). The scores for nurse intervention were dichotomized into those who consistently delivered intervention (always/usually) versus those who were not consistent in their delivery of intervention (sometimes/rarely/never). We used Generalized Linear Mixed Model to analyze change in intervention from baseline to 3 months.

\section{RESULTS}

Table 1 shows the nurse respondents' demographic data. There were only 5 men among the 279 nurses, and the sample consisted of mostly "general registered nurses" (67\% of the respondents), with an average age of 42 years, and an average of 20 years of work experience, varying between medical and surgical units or ambulatory clinics. At present, $17 \%$ of the respondents were smokers, and 26\% were former smokers (Table 1).
Nurses' use of the brief intervention method increased to a statistically significantly degree after e-learning: asking about smoking (always/usually) increased from $58 \%$ to $69 \%$; recommendations to quit smoking rose from $56 \%$ to $66 \%$; assessing willingness to quit increased from $49 \%$ to $63 \%$; assisting with cessation rose from $21 \%$ to $33 \%$; and recommending a smoke-free home improved from $39 \%$ to $58 \%$. However, the frequency of arranging control visits increased only from $7 \%$ to $10 \%$, which was not statistically significant. Even though the quit line recommendation increased from $21 \%$ to $34 \%$, at present the quit line operates only partially and has no continuous support (Table 2 ).

\section{DISCUSSION AND CONCLUSION}

Although the results are not ideal, they are even more disappointing after considering the fact that likely these respondents are more motivated than an average nurse, as they expressed interest in their education. In addition, the prevalence of smoking among the surveyed nurses was less than half of that noted in the general population, at a rate of only $17 \%$ in the survey, compared to approximately $40 \%$ estimated prevalence of all Czech nurses. Comparing the Czech results, for example, in the USA only $7 \%$ of nurses smoke, $64 \%$ of local nurses ask patients about smoking, $38 \%$ assess the patient's readiness to quit, and $32 \%$ recommend quitting. Moreover, nearly two thirds of US nurses (64\%) evaluate and document the patient's smoking status (5). US activity in patient intervention is also higher than in the Czech Republic, but even so, the authors consider it as low. Among the surveyed Czech nurses, $36 \%$ intervened, $32 \%$ recommended quitting, $24 \%$

Table 2. Nurses attitudes to influencing smoking habits in patients

\begin{tabular}{|l|c|c|c|}
\hline $\begin{array}{l}\text { Table lists average value on 5-point scale (strongly agree/agree/do not know/disa- } \\
\text { gree/strongly disagree) }\end{array}$ & $\begin{array}{c}\text { Before e-learning } \\
\text { Mean (SD) }\end{array}$ & $\begin{array}{c}3 \text { month after } \\
\text { e-learning } \\
\text { Mean (SD) }\end{array}$ & p value \\
\hline Nurses should be non-smoking example ( $=275)$ & $4.21(0.93)$ & $4.27(0.95)$ & 0.0881 \\
\hline Nurses should help patients quit smoking ( $\mathrm{N}=271)$ & $4.05(0.76)$ & $4.01(0.87)$ & 0.8488 \\
\hline Nurses need training in interventions and education in tobacco control (N=271) & $3.88(0.88)$ & $3.94(0.93)$ & 0.0890 \\
\hline It is important for nurses to be active in tobacco control ( $\mathrm{N}=276)$ & $3.54(0.98)$ & $3.83(1.03)$ & $<0.001$ \\
\hline Is tobacco control compared with other activities in disease prevention important? $(\mathrm{N}=272)$ & $3.53(0.92)$ & $3.67(0.99)$ & 0.0068 \\
\hline
\end{tabular}

Only nurses who answered both questionnaires (baseline and 3 months after training) were included, $\mathrm{N}=279$. Answers of less than 279 mean that not all respondents answered to all questions.

Table 3. Nursing intervention in smokers - short intervention

\begin{tabular}{|l|c|c|c|c|c|}
\hline & $\begin{array}{c}\text { Before e-learning } \\
\mathbf{n}(\%)\end{array}$ & $\begin{array}{c}3 \text { months after } \\
\text { e-learning } \\
\mathbf{n}(\%)\end{array}$ & OR & Cl & p value \\
\hline I ask about smoking ( $=279)$ & $161(57.71)$ & $192(68.82)$ & 1.62 & $1.14-2.29$ & 0.007 \\
\hline I advice to stop ( $\mathrm{N}=274)$ & $160(57.55)$ & $182(66.42)$ & 1.46 & $1.03-2.06$ & 0.030 \\
\hline I assess readiness to quit (N=275) & $138(49.46)$ & $172(62.77)$ & 1.72 & $1.23-2.42$ & 0.002 \\
\hline I assist with quitting ( $=273)$ & $58(20.86)$ & $89(32.72)$ & 1.85 & $1.26-2.71$ & 0.002 \\
\hline I arrange for control $(\mathrm{N}=273)$ & $20(7.22)$ & $28(10.29)$ & 1.48 & $0.81-2.69$ & 0.200 \\
\hline I recommend quit line $(\mathrm{N}=273)$ & $58(20.79)$ & $93(34.19)$ & 1.98 & $1.35-2.90$ & $<0.001$ \\
\hline I recommend smoke-free home $(\mathrm{N}=274)$ & $108(38.85)$ & $158(57.88)$ & 2.16 & $1.54-3.04$ & $<0.001$ \\
\hline
\end{tabular}


recommended nicotine replacement therapy, and $16 \%$ provided advice on avoiding relapses.

The barriers identified in our sample include a lack of patient motivation (74\%), a lack of time for nurses to spend with patients $(52 \%)$, and insufficient nurse training $(53 \%)$. By contrast, most American nurses would like to help smokers quit (88\%); however, they would like to be better educated in accomplishing this task (92\%) (10). While a persistently low number of arranged visits in connection with nurses' status in the Czech Republic is understandable, a significant improvement in nurses' knowledge and their ability to use brief interventions after completing a relatively short and readily available educational programme suggests that this type of activity should be given more attention (11).

In conclusion, increasing the knowledge of Czech nurses, their self-confidence in dealing with smokers as well as their sense of responsibility and ownership pertaining to these interventions, may not always be ideal, nevertheless, e-learning education is an effective and affordable method to improve the current situation (12).

\section{Conflict of Interests}

None declared

\section{Acknowledgements}

This study was approved by the Ethical Committee of the Faculty Hospital in Prague, Czech Republic, and sponsored by the Eastern Europe - Helping Smokers Quit Project. This project was supported by a grant to the International Society of Nurses in Cancer Care (ISNCC) from the Bristol-Myers Squibb Foundation, Bridging Cancer Care; the UCLA Lulu Wolf Hassenplug Endowed Chair fund provided additional funding to support the analysis. We thank Derek Noland of the University of Colorado, Behavioral Health and Wellness Program, for his review and proofreading.

\section{REFERENCES}

1. Peto R, Lopez AD, Boreham J, Thun M. Mortality from smoking in developed countries 1950-2005 (or later), update March 2012 [Internet]. Oxford: Oxford University Press; 2012 [cited 2016 Mar 21]. Available from: http://www.ctsu.ox.ac.uk/ tobacco/.

2. Sovinová H, Csémy L. The use of tabacco in the Czech Republic 2015 [Internet]. Prague: National Institute of Public Health; 2016 [cited 2016 Mar 21]. Available from: http://www.szu.cz/uploads/documents/czzp/ zavislosti/Uzivani_tabaku_2015.pdf. (In Czech.)

3. World Health Organization. WHO Report on the Global Tobacco Epidemic, 2008: the MPOWER package. Geneva: WHO; 2008.

4. Králíková E. Smoking of health care professionals. In: Králíková E, editor. Tobacco dependence - epidemiology, prevention and treatment. Breclav: Adamira; 2013. p. 63-64. (In Czech.)

5. Sarna L, Bialous SA, Nandy K, Antonio AL, Yang Q. Changes in smoking prevalences among health care professionals from 2003 to 2010-2011. JAMA. 2014 Jan 8;311(2):197-9.

6. Fiore MC, Jaén CR, Baker TB, Bailey WC, Benowitz NL, Curry SJ, et al. Treating tobacco use and dependence: 2008 update. Clinical practice guideline. Rockville (MD): U.S. Department of Health and Human Services; 2008.

7. Malá K, Felbrová V, Kulovaná S, Nohavová I. Tobacco dependence: information and intervention guidelines for nurses. Prague: SLZT; 2015. (In Czech.)

8. Sarna LP, Brown JK, Lillington L, Rose M, Wewers ME, Brecht ML. Tobacco interventions by oncology nurses in clinical practice: report from a national survey. Cancer. 2000 Aug 15;89(4):881-9.

9. Browning KK, Wewers ME. Smoking cessation and cancer. Semin Oncol Nurs. 2003 Nov;19(4):268-75.

10. Sarna L, Bialous SA, Wells M, Kotlerman J, Wewers ME, Froelicher ES. Frequency of nurses' smoking cessation interventions: report from a national survey. J Clin Nurs. 2009 Jul;18(14):2066-77.

11. Sarna LP, Bialous SA, Kraliková E, Kmetova A, Felbrová V, Kulovaná $\mathrm{S}$, et al. Impact of a smoking cessation educational program on nurses' interventions. J Nurs Scholarsh. 2014 Sep;46(5):314-21.

12. Sarna LP, Bialous SA, Králíková E, Kmetova A, Felbrová V, Kulovaná $\mathrm{S}$, et al. Tobacco cessation practices and attitudes among nurses in the Czech Republic. Cancer Nurs. 2015 Nov-Dec;38(6):E22-9.

Received December 8, 2015 Accepted in revised form October 26, 2016 